Review

\title{
Human Papillomavirus, Human Immunodeficiency Virus and Immunosuppression
}

\author{
Lynette A. Denny ${ }^{\mathrm{a}, *}$, Silvia Franceschi ${ }^{\mathrm{b}}$, Silvia de Sanjoséc,d, Isabelle Heard ${ }^{\mathrm{e}}$, \\ Anna Barbara Moscicki ${ }^{\mathrm{f}}$, Joel Palefsky ${ }^{\mathrm{g}}$
}

a Department Obstetrics and Gynaecology and Institute of Infectious Diseases and Molecular Medicine, University of Cape Town/Groote Schuur Hospital, Cape Town, South Africa

b International Agency for Research on Cancer, 150 cours Albert Thomas, 69372 Lyon cedex 08 France

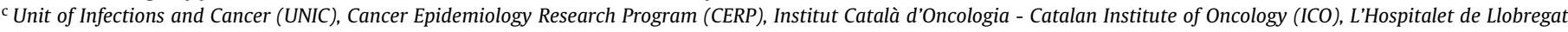
(Barcelona), Spain

d CIBER en Epidemiología y Salud Pública (CIBERESP), Spain

e National Reference Centre for HPV, Groupe Hospitalier Pitie- Salpetriere, INSERM, U943;UPMC Universite, Paris, France

${ }^{f}$ Professor of Paediatrics, University of California, San Francisco, USA

${ }^{g}$ Professor of Medicine, Division of Infectious Diseases, University of California, San Francisco, USA

\section{A R T I C L E I N F O}

\section{Article history:}

Received 13 January 2012

Received in revised form 2 May 2012

Accepted 12 June 2012

\section{Keywords:}

HPV

HIV

Immunosuppression

Cervical cancer prevention

HPV vaccination

Anal cancer

Perinatal transmission

Male circumcision

\begin{abstract}
A B S T R A C T
The vast majority of women infected with human immunodeficiency virus (HIV) will be co-infected with human papillomavirus (HPV). The interaction between the two sexually transmitted infections appears to be related to the alteration in cell-mediated immunity in HIV infected persons, increased susceptibility, and possibly reactivation of latent HPV infection. Linkage studies of HIV/AIDs and Cancer registries have indicated a 2- to 22-fold increase in cervical cancer in HIV-positive women compared to HIV-negative women. Data on the prevalence of HPV types in invasive cervical carcinoma (ICC) suggest that the proportion of infection with types HPV16/18 (responsible for over 70\% of all cervical cancers) is similar in HIV-negative and HIV-positive women. The biological interaction between HIV and HPV needs further elucidation, although there is some evidence that the presence of HPV infection may be associated with increased HIV transmission. Adolescents perinatally infected by HIV are known to have higher rates of HPV infection and also have been shown to seroconvert in response to HPV vaccination with the quadrivalent vaccine, albeit to lower titers than HIV-negative individuals. Anal cancer incidence is greatly increased in HIV-positive individuals, particularly in HIV-positive men who have sex with men. Screening for anal cancer precursors is feasible and effective; however, the impact on reduction of anal cancer remains to be demonstrated. There are ongoing studies on the safety, immunogenicity, and efficacy of current HPV vaccines in HIV-positive individuals and mature data are awaited. Male circumcision may be another approach to prevention of HPV transmission, which also requires further study.

This article forms part of a special supplement entitled "Comprehensive Control of HPV Infections and Related Diseases" Vaccine Volume 30, Supplement 5, 2012.
\end{abstract}

(c) 2012 Elsevier Ltd. All rights reserved.

\section{Introduction}

It is now well established that human immunodeficiency virus (HIV) infection increases the risk of developing certain cancers and Kaposi's sarcoma, non-Hodgkin's lymphoma and cervical cancer have been classified as AIDS (acquired immunodeficiency syndrome) defining diseases since 1993 [1]. Linkage studies between HIV/AIDS and cancer registries have shown a 2- to 22-fold increased incidence of invasive cervical cancer (ICC) in HIV-positive women compared to the general female population from the same area,

\footnotetext{
* Corresponding author. Tel.: +27 21404 4485; fax: +27 214486921

E-mail address: Lynette.denny@uct.ac.za (L.A. Denny).
}

depending upon the life expectancy of HIV-positive women and the coverage and quality of cervical cancer screening in different countries. HIV-positive women have also been shown to be at increased risk for human papillomavirus (HPV) infection and progression to cervical intraepithelial neoplasia grade 3 (CIN3) [2].

Infection with HPV is the most common sexually transmitted infection (STI) worldwide. Women infected with HIV have consistently been shown to have higher prevalence of HPV infection, persistent infection with HPV, infection with multiple types of HPV, and cervical cancer precursors than HIV-uninfected women [3-5]. Clifford GM et al. [6] performed a meta-analysis of 20 studies that identified 5578 HIV-positive women who underwent cytology and HPV genotyping. HPV prevalence in HIV-positive women with normal cytology was $36.3 \%$ for any HPV and $12 \%$ for multiple types of 
HPV, with the six most common types being HPV16, 58, 18, 52, 31 and 33. In HIV-positive women in different regions of the world, the equivalent findings for HPV positivity were: 31\% (Asia), 31\% (United States of America [USA]), 57\% (South/Central America) and $57 \%$ (Africa).

In a recent cross-sectional study of women at high risk for STIs from Rwanda, prevalence of any HPV was 47\% in HIV-negative women (mean age 25 years) compared to $72 \%$ in HIV-positive women (median age 27 years) [7]. The increased incidence, prevalence and persistence of HPV infection in HIV-positive women is attributed to increased susceptibility, decreased ability to clear infection due to impaired cell-mediated immunity, and reactivation of latent HPV infection associated with immunosuppression [8]. Infection with high-risk types of HPV (hrHPV) is etiologically associated with the development of cervical cancer, and is associated with other anogenital tract cancers (anus, vulva, vagina, penis) and a proportion of oropharyngeal cancers $[9,10]$. The expected increase in anogenital cancers in HIV-positive individuals has recently become apparent, with increases in cervical cancer and anal cancer being well documented [11,12]. The impact of Highly Active Antiretroviral Therapy (HAART) on HPV infection and its sequelae has been controversial to date, with some studies showing regression and others no impact on HPV-associated disease. Minkoff $\mathrm{H}$ et al. [13] reported on a prospective study of 286 HIV-positive women who initiated HAART during the followup period. They found a significant reduction in prevalence and incidence of oncogenic HPV infection, and more rapid clearance of oncogenic HPV-associated squamous intraepithelial lesions, particularly among HAART-adherent women.

\section{Prevalence of HPV types in HIV-infected women with normal cytology, cervical cancer precursors, and cervical cancer}

A meta-analysis of HPV prevalence in HIV-positive women worldwide showed a relative underrepresentation of HPV16 and overrepresentation of the other hrHPV types in HIV-positive compared to HIV-negative women with or without cervical abnormalities [6]. The lower prevalence of HPV16 in CIN2/3 (the endpoint lesions used in the evaluation of HPV vaccine efficacy) suggested that vaccination may prevent a smaller proportion of ICC in HIVpositive compared to HIV-negative women.

A recent meta-analysis by Li $\mathrm{N}$ et al. [14] found that HPV16 and 18 (the hrHPV types targeted by the current prophylactic HPV vaccines) are found in $57 \%$ and $16 \%$ of cervical carcinomas, respectively, in the general female population worldwide. Information on HPV types in HIV-positive women with ICC is, however, scarce [15].

To date, there are only a few small studies from South Africa, Kenya and Zambia that have examined HPV type distribution in ICC in HIV-positive women. Overall, these studies have shown that the proportion of HPV16 and/or 18 in ICC in HIV-positive women ranges from 53.6-86.0\% [15-18]. These studies are summarized in Table 1. Unfortunately, some of these studies did not include HPV type by HIV characteristics, such as CD4 counts, viral loads and clinical stage of disease. In a more recent study, De Vuyst $\mathrm{H}$ et al. [17] compared HPV infections in 106 HIV-positive and 129 HIVnegative women diagnosed with squamous cell cervical carcinoma. Among HIV-positive women, the mean CD4 count was 334 cells $/ \mu \mathrm{L}$ and $48.1 \%$ were on combined antiretroviral therapy. HIV-positive women had many more multiple HPV infections (21.6\% of HPVpositive carcinomas) compared to HIV-negative women (3.3\%) $(p<$ 0.001 ). The proportion of multiple infections was negatively associated with CD4 level. An excess of HPV18 was found in HIV-positive compared to HIV-negative cases (prevalence ratio $[\mathrm{PR}]=1.9,95 \%$ confidence interval (CI): 1.0-3.7, adjusted for study centre, age and multiplicity of infection). HPV16 and/or 18 prevalence combined

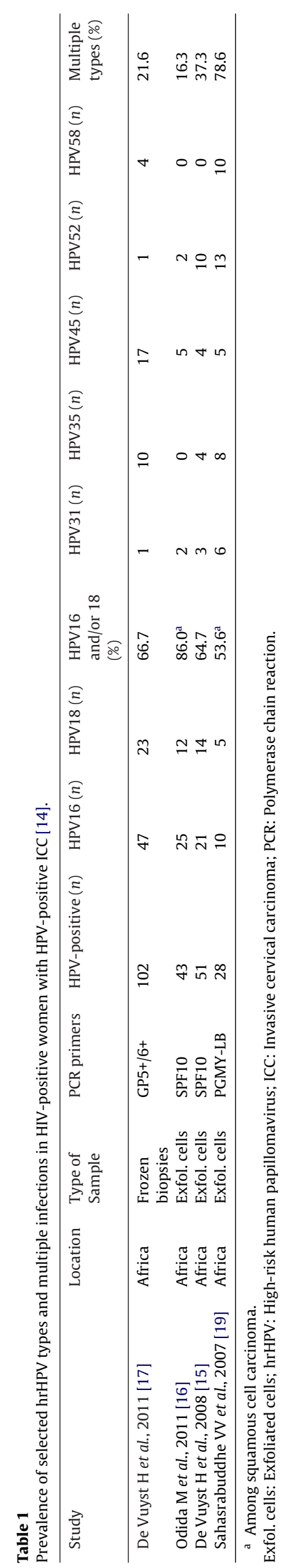


was similar in HIV-positive (66.7\%) and HIV-negative cases (69.1\%) $(P R=1.0,95 \% C I: 0.9-1.2)$. No significant differences emerged for other hrHPV types and single infections with low-risk types were very few $(<3 \%)$ regardless of HIV status.

Naucler $\mathrm{P}$ et al. [18] performed a hospital-based case-control study at the Central Hospital in Maputo, Mozambique. They recruited 221 women with cervical cancer and 203 hospital-based controls. Among women with cervical cancer, 49 (22\%) were HIVpositive. HPV16 was found in $49.8 \%$ of cases and $6.4 \%$ of controls and HPV18 in $20.4 \%$ and $3.0 \%$, respectively. The next most common type found in the cases was HPV45 (14.5\% cases and 3\% controls). Highrisk non-HPV16 or 18 types were found in $29.4 \%$ of cases and $18.2 \%$ of controls. When stratified by HIV status, $40.8 \%$ of the HIV-positive cases were HPV16-positive, 26.5\% were HPV18-positive, and $30.6 \%$ were high-risk non-HPV16/18 positive. Among HIV-negative women with cervical cancer, 52.2\% were HPV16-positive, $19.1 \%$ were HPV18-positive and $27.4 \%$ were high-risk non-HPV16/18positive. The authors concluded that HIV infection did not modify significantly the distribution of HPV types in cervical cancer.

The reported proportion of HPV16 and/or 18 in HIV-positive women is compatible with the $71 \%$ prevalence of HPV16 and/or 18 seen in cervical cancer in sub-Saharan Africa [19], and to the range of prevalences found in ICC in developed countries (Europe and North America combined: 73.2\%) [20].

These data suggest that the available prophylactic HPV vaccines against HPV16 and 18 may prevent a similar proportion of ICCs, regardless of HIV status, provided vaccine-related protection is sustained after HIV infection.

\section{Biological interaction between HPV and HIV}

Immunocompromised individuals, such as those with HIV, not only have higher rates of HPV and ICC, but are also resistant to treatment of HPV-related diseases and prone to accelerated development of HPV-associated cancer [21]. In multivariate analysis, low CD4+ counts ( $\leq 200$ cells $/ \mu \mathrm{L}$ ) have been shown to be the strongest independent predictor of infection with hrHPV genotypes and increased risk of genital warts [22]. Furthermore, HIV-infected patients with genital warts show more resistance to treatment and women treated for CIN are more likely to relapse.

Several studies have suggested that HIV is independently associated with HPV acquisition and morbidity. It is, however, unknown whether the converse relationship is also true, i.e., whether HPV infection affects the risk of HIV acquisition. Some of the common sexually transmitted infections have been postulated to increase the risk of HIV acquisition, including syphilis, herpes simplex virus (HSV)-2, Neisseria gonorrhea, Chlamydia trachomatis and Trichomonas vaginalis. Data on a potential link with HPV and HIV are limited but suggest a similar effect.

Follow-up of 1409 men having sex with men (MSM) from the USA showed that having an HPV infection significantly increased the risk of HIV seroconversion (hazard ratio $[\mathrm{HR}]=3.5,95 \% \mathrm{CI}$ : 1.2-10.6) [23]. The association persisted after adjustment for sexual activity, substance use, occurrence of other STIs and demographic variables. A randomized clinical trial evaluating HPV infection and circumcision among 2168 young men in Kenya explored the association between HPV and HIV infection [24]. HPV infection was independently associated with an increased risk of HIV acquisition over 42 months of follow-up with a cumulative incidence of 5.3\% (95\% CI: 3.4-7.2) in HPV-positive men versus 4.0\% (95\% CI: 1.9-6.1) in HPV-negative men $(p=0.04)$. The risk persisted after adjustment for HSV-2 serostatus, gonorrhea, chlamydial infection, and other possible confounders.

Similar observations were seen for women in a prospective cohort study of 2040 HIV-negative Zimbabwean women who were followed for a median of 21 months [25]. Woman who participated in the study were tested for 29 HPV DNA types (with L1 polymerase chain reaction [PCR] primers) and HIV (antibody testing on blood samples with DNA or RNA PCR confirmation). Baseline HIV incidence was 2.7 per 100 woman-years and baseline HPV prevalence was $24.5 \%$. HIV acquisition was associated with detection of any oncogenic HPV type within the previous 6 months (adjusted $\mathrm{HR}=1.95,95 \% \mathrm{CI}: 1.19-3.21$ ) even when new partners and high-risk behavior of the members of the couple were controlled for in the analysis. An interesting observation of the study was that the finding was restricted to new HPV infections and not persistent infections. It can be postulated that the new infections are more likely to elicit a local immune response in an attempt to clear the HPV infection. The local response to HPV infection solicits immune cells which may be vulnerable to infection with HIV. HPV-associated lesions such as warts, CIN or cancer are known to be infiltrated by regulatory $\mathrm{T}$-cells and macrophages which are targets of HIV infection [23,24].

Taken together, behavioral, immunologic and genetic data suggest a complex interaction between HIV and HPV. Further study is warranted and a greater understanding may facilitate the development of preventive strategies for both HIV and HPV related disease.

\section{HPV in perinatally HIV-infected children and adolescents}

Although HPV transmission from mother to infant has been documented, persistence of HPV in the oral cavity or genitals of immunocompetent children appears to be low. In one study, acquisition of HPV occurred postnatally and persistent infection in children was associated with persistent infection in their respective parents, suggesting that transmission can also occur postnatally. Little to nothing is known about the natural history of HPV infection in children or adolescents with perinatallyacquired HIV infection [26,27]. Only one study reported on the HPV-associated morbidity among perinatally infected adolescents. Although this study did not test for HPV DNA and there were no control group, it reported that $47.5 \%$ of the sexually active perinatally HIV-infected adolescents had abnormal cytology-a rate that is 3-4 times higher than those seen in HIV-uninfected adolescents [27]. Cytologic abnormalities are thought to be more likely derived from recent sexually transmitted HPV infection (in combination with immunosuppression) than from perinatally acquired infection. The follow-up in this cohort showed that during the period 2001-2006, the prevalence of gynecologic dysplasia in adolescents perinatally infected by HIV increased, whereas the prevalence of gynecologic dysplasia in adolescents affected by other conditions, including neurologic and cardiac disease, decreased, suggesting that HAART did not influence HPV-associated disease. There have been sporadic case reports of genital cancers in perinatally HIV-infected children. Although there have been no case-control studies, an excess of oral and genital condyloma have been described in HIV-infected children [27,28]. Only one study showed data on oral HPV infection in perinatally HIV-infected children. Among 50 HIV-infected children, 12\% had HPV DNA detected, compared to $6 \%$ of the HIV-negative children [29].

Many questions remain regarding the efficacy of HPV vaccines in HIV-infected children and the duration of the efficacy. Data from one study of perinatally infected children showed that, although seroconversion was close to 100\%, antibody titers for HPV16 and 18 after vaccination with the quadrivalent vaccine (Gardasil ${ }^{\circledR}$ Merck \& Co., Whitehouse Station, NJ USA) were lower than that for nonimmunocompromised children [30].

\section{Anal cancer screening in HIV-infected women and men}

Anal cancer is similar to cervical cancer biologically, and both are caused by HPV, predominantly HPV16 [31,32]. Screening programs 
consisting of cytology to identify women with CIN2/3, followed by treatment of the lesion after confirmation on colposcopic-directed biopsy, have led to substantial reductions in the incidence of cervical cancer. Similarly, the equivalent to $\mathrm{CIN} 2 / 3$, high-grade anal intraepithelial neoplasia (HGAIN, AIN 2/3) is the precursor of anal cancer [33]. Given the biological similarity between cervical and anal cancer, and CIN and AIN, it is likely, albeit unproven, that removal of HGAIN may reduce the risk of anal cancer.

While anal cancer is a relatively rare cancer in the general population, its incidence has been increasing among both men and women by about $2 \%$ per year [34]. The incidence of anal cancer is increased among HIV-infected compared to non-infected women and men, regardless of mode of HIV acquisition, but is especially high among MSM [35]. HIV-infected women were at nearly 7-fold increased risk of anal cancer compared with the general population of women prior to the advent of HAART. In contrast to the effect of HAART on AIDS-defining malignancies such as Kaposi's sarcoma and non-Hodgkin's lymphoma, there is no evidence for a substantial beneficial effect of HAART on the incidence of HGAIN, regression of existing lesions, or clearance of HPV infection itself in either men or women [36]. Consistent with this, the incidence of anal cancer has continued to increase since the introduction of ART. According to data from the HIV/AIDS cancer Match Study (which links 15 HIV and cancer registries in the USA), the largest increase in non-AIDS defining cancers has been seen for anal cancer: from 1991-1995 to 2001-2005, the reported cases of anal cancer increased from 206 to 1564 [37]. Most HIV-positive individuals currently do not undergo screening or treatment for HGAIN, and the longer survival time afforded by HAART may give an HGAIN lesion more time to progress to cancer.

Like the cervical cytology screening program, an anal cytology screening program is primarily focused on cancer prevention, not cancer detection. Anal cytology and high resolution anoscopy (HRA)-guided biopsy are aimed at identifying cancer at early stages before it can be palpated clinically, and treating HGAIN before it progresses to cancer [38]. Digital anorectal exam (DARE) is an important cancer detection tool, in which the clinician palpates the anal canal and peri-anal region for masses. This is important, since DARE may identify cancers not visible on HRA.

Currently, the primary screening tool for anal HPV-associated diseases is cytology, in which the grading system used in the United States is the Bethesda 2001 system [38]. As in the cervix, treatment decisions for AIN are based on histology and not cytology grade. If screening is performed, individuals with an abnormal anal cytology should be referred for HRA and anal biopsy, with treatment decisions based on the grade of the lesion on histology. Several different methods of performing anal cytology have been described, but the most commonly used method is blind insertion of a moistened nylon swab as far as possible into the anal canal and rectum, followed by insertion of the swab into a liquid cytology bottle and vigorous shaking of the swab to dislodge cells. Anal cytology is similar to cervical cytology in its performance characteristics [38]. However, unlike the cervix, where the value of screening for and treatment of high-grade CIN to prevent cervical cancer is well established, there is little evidence on the effectiveness of diagnostic and treatment protocols for HGAIN and the effectiveness of treatment of HGAIN to prevent anal cancer. No randomized clinical trials have been performed to validate the efficacy on any type of screening for anal cancer and no national screening guidelines are available. Most cytologists have limited experience with interpreting anal samples [39]. In addition, as a technique, HRA is more challenging than traditional cervico-vaginal colposcopy and the number of skilled HRA providers is limited, even in the highestresource countries. Cost-effectiveness studies have been done in HIV-infected adult MSM [40] but none have been reported yet for HIV-infected women. Given the current knowledge and experience gap, efforts in the evaluation and implementation of anal cancer screening in high resource countries should concentrate on the highest risk groups (i.e., HIV-infected adult MSM).

\section{Options for primary prevention of HPV infection in HIV-positive individuals}

\subsection{HPV vaccination in HIV-infected individuals}

HIV-infected women present with higher rates of anal and cervical HPV infection and of HPV-related diseases and cancers compared with HIV-uninfected women in every world region. As treatment options for HPV-associated diseases remain limited in this population, there are opportunities for disease prevention with vaccination and there is a rationale to give high priority to introducing HPV vaccination to populations in whom the prevalence of HIV infection is high, notably in sub-Saharan African countries.

Two prophylactic HPV vaccines, one bivalent (Cervarix ${ }^{\circledR}$, GlaxoSmithKline Biologicals, Rixensart, Belgium) and one quadrivalent $\left(\right.$ Gardasil $\left.{ }^{\circledR}\right)$, have been developed, tested in clinical trials and licensed in over 100 countries since 2006. They have only been included in national vaccination programs in high-resource countries. Both vaccines have been shown to prevent nearly $100 \%$ of persistent HPV16 and 18 infection and high-grade lesions caused by these types in women not previously infected below the age of 26 years. The quadrivalent vaccine also protects against low-risk genotypes 6 and 11 and, hence, genital warts. For the bivalent vaccine, vaccine efficacy has been shown against anal HPV infection in women. No data are currently available on HPV vaccine efficacy in HIV-infected people.

As with perinatally infected children, the safety and immunogenicity of both HPV vaccines are currently being evaluated in HIV-infected adults. The quadrivalent vaccine appears to be safe and immunogenic in HIV-infected infants (Table 2). Two studies will provide information on immunogenicity and safety of the quadrivalent vaccine in HIV-infected adolescents (http://clinicaltrials.gov, December 1, 2011, Table 2). One of these studies has as secondary objectives, to determine 1) any differences in antibody titers between HIV-infected and HIV-negative subjects and 2) differences in antibody titers among HIV-positive subjects on versus those not on antiretroviral therapy.

Five studies are currently ongoing in HIV-infected adolescent girls and young women, to evaluate the safety, tolerability, and immunogenicity of HPV vaccines (http://clinicaltrials.gov, December 1, 2011, Table 2). The quadrivalent vaccine is being evaluated in three studies and the bivalent in one study, whereas one study will compare safety and immunogenicity of the bivalent and the quadrivalent vaccine (Clinical trials registration: NCT01031069). Only one study will have clinical endpoints: prevalence and incidence of CIN in patients and description of the spectrum of cervical HPV types at baseline, 9 months, and 1 year after vaccination (Clinical trials registration: NCT00667563).

Safety and immunogenicity of the bivalent vaccine have been evaluated in a Phase II interventional study in South Africa (Clinical trials registration: NCT00586339). Preliminary results were presented at AORTIC 7th International Conference, November 2011, Cairo Egypt [41]. The study showed that regardless of baseline HPV status, all HIV-positive and HIV-negative subjects had seroconverted to HPV16/18 at Month 2 and Month 7. Nevertheless, as observed in HIV-infected infants [30], geometric mean titers appeared to be significantly lower in the HIV-positive women compare with HIV-negative women.

Whereas all these trials will provide much needed data on the safety, immunogenicity, and, to lesser extent, efficacy of HPV vaccines in HIV-infected women, their findings will only apply to individuals similar to the trial population. For HIV-positive men 
Table 2

Clinical trials designed to evaluate the safety and immunogenicity of HPV vaccines in HIV-infected infants and females (ClinicalTrials.gov, January 2, 2012).

\begin{tabular}{|c|c|c|c|c|c|c|}
\hline Participants & $\begin{array}{l}\text { Clinicaltrials.gov } \\
\text { identifier }\end{array}$ & Sponsor & Location & Vaccine & Status & Study \\
\hline $\begin{array}{l}180 \text { HIV-infected girls and boys } \\
\text { aged } 9-14 \text { years }\end{array}$ & NCT01446718 & Nelly R Mugo & Kenya & Quadrivalent & $\begin{array}{l}\text { Not yet } \\
\text { recruiting }\end{array}$ & $\begin{array}{l}\text { Immunogenicity and safety of } \\
\text { the quadrivalent vaccine }\end{array}$ \\
\hline $\begin{array}{l}105 \text { HIV-infected and HIV-negative } \\
\text { adolescents and young adults } \\
\text { aged } 12-26 \text { years }\end{array}$ & NCT00798265 & $\begin{array}{l}\text { National Cancer } \\
\text { Institute }\end{array}$ & USA, Maryland & Quadrivalent & Recruiting & $\begin{array}{l}\text { Safety and immunogenicity on } \\
\text { HIV-infected compared to } \\
\text { HIV-negative persons of the } \\
\text { same age }\end{array}$ \\
\hline $\begin{array}{l}99 \text { HIV-infected women aged } \\
16-23 \text { years }\end{array}$ & NCT00710593 & NICHD & $\begin{array}{l}\text { USA } \\
\text { Puerto Rico }\end{array}$ & Quadrivalent & Completed & $\begin{array}{l}\text { Immunogenicity, safety, } \\
\text { tolerability, and behavioral } \\
\text { impact } \\
\text { Participants divided in two } \\
\text { arms according to immune status } \\
\text { and duration and efficacy of } \\
\text { antiretroviral therapy }\end{array}$ \\
\hline $\begin{array}{l}282 \text { HIV-infected women aged } \\
13-45 \text { years }\end{array}$ & NCT00604175 & NIAID & $\begin{array}{l}\text { USA } \\
\text { Brazil } \\
\text { Puerto Rico } \\
\text { South Africa }\end{array}$ & Quadrivalent & $\begin{array}{l}\text { Ongoing, not } \\
\text { recruiting }\end{array}$ & $\begin{array}{l}\text { Phase II study to evaluate safety, } \\
\text { tolerability, and immunogenicity } \\
\text { of HPV vaccine } \\
\text { Participants will be divided in } 3 \\
\text { arms according to level of } \\
\text { immunosuppression }\end{array}$ \\
\hline $\begin{array}{l}150 \text { HIV-infected females aged } 18 \\
\text { years or older }\end{array}$ & NCT00667563 & $\begin{array}{l}\text { AIDS Malignancy } \\
\text { Clinical Trials } \\
\text { Consortium }\end{array}$ & India & Quadrivalent & $\begin{array}{l}\text { Ongoing, not } \\
\text { recruiting }\end{array}$ & $\begin{array}{l}\text { To assess the safety of the } \\
\text { quadrivalent vaccine in women } \\
\text { without prior exposure to at } \\
\text { least one of the HPV types in the } \\
\text { vaccine } \\
\text { Only study with clinical } \\
\text { endpoints: prevalence and } \\
\text { incidence of cervical } \\
\text { intraepithelial neoplasia in } \\
\text { patients and description of the } \\
\text { spectrum of cervical HPV types } \\
\text { at baseline, } 9 \text { months, and } 1 \text { year } \\
\text { after vaccination }\end{array}$ \\
\hline $\begin{array}{l}120 \text { HIV-infected adult females } \\
\text { aged } 18-25 \text { years and } 30 \\
\text { HIV-negative females }\end{array}$ & NCT00586339 & GlaxoSmithKline & South Africa & Bivalent & Completed & $\begin{array}{l}\text { To evaluate safety and } \\
\text { immunogenicity of the Bivalent } \\
\text { vaccine. Double blinded, } \\
\text { randomized for HIV-positive } \\
\text { subjects and open for } \\
\text { HIV-negative subjects }\end{array}$ \\
\hline $\begin{array}{l}600 \text { HIV-infected females aged } \\
15-25 \text { years }\end{array}$ & NCT01031069 & GlaxoSmithKline & $\begin{array}{l}\text { Brazil } \\
\text { India } \\
\text { Thailand }\end{array}$ & $\begin{array}{l}\text { Bivalent } \\
\text { Quadrivalent }\end{array}$ & $\begin{array}{l}\text { Ongoing, not } \\
\text { recruiting }\end{array}$ & $\begin{array}{l}\text { Phase IV, observer-blind study } \\
\text { designed to evaluate the safety } \\
\text { and immunogenicity of the } \\
\text { bivalent vaccine as compared to } \\
\text { the quadrivalent vaccine }\end{array}$ \\
\hline
\end{tabular}

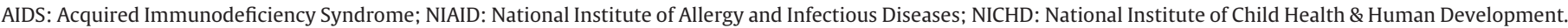

and women, particularly those older than 25 years, efforts should concentrate on cervical cancer screening.

Several studies have estimated the impact of HPV vaccination on HPV prevalence and cervical cancer incidence in developed countries with very low prevalence of HIV infection. Development of specific models for developing countries should take into account the prevalence of HIV, which can be as high as $30 \%$, and the fact that HIV-infected women are at higher risk for developing cervical cancer than women from the general population.

The World Health Organization (WHO) recommends HPV vaccination of girls aged 9-13 years through national immunization programs in countries where cervical cancer constitutes a significant public health problem. The best example is represented by low-resource countries where cervical cancer is the most common cancer cause of death in women, such as in sub-Saharan Africa, and where the prevalence of HIV infection and AIDS is also high. Clinics providing care to men and women with HIV/AIDS need to be aware of association between HIV and HPV-related disease and should be providing prevention services, including cervical screening.

\subsection{Male circumcision}

Three randomized controlled trials have shown that circumcision reduces the risk of HIV transmission in heterosexual men by about $60 \%$ and the WHO has recommended that circumcision be added to current HIV prevention strategies. These three trials were conducted in South Africa $(n=3274)$, Uganda $(n=4996)$ and Kenya ( $n=2784$ ) between 2002 and 2006 [42]. Siegfried N et al. [42] combined the findings of all three trials at 12, 21 or 24 months in a meta-analysis. The reduction in risk of acquiring HIV following circumcision was $50 \%$ at 12 months and $54 \%$ at 21 or 24 months. Male circumcision has also been shown to reduce the risk of other sexually transmitted infections including T. vaginalis, HSV-2 and genital ulcer disease [42-44]. The data on male circumcision and prevention of HPV infection have been inconsistent, possibly due also to different methodologies used for sampling anatomical sites and HPV testing.

Larke $\mathrm{N}$ et al. published a systematic review and meta-analysis on male circumcision and HPV infection in men [45]. They identified 23 papers about the association between circumcision and 
HPV DNA. Circumcised men were less likely to have prevalent genital HPV infection than uncircumcised men (summary odds ratio 0.57, 95\% CI: 0.45-0.71). The effect of circumcision was stronger at the glans/corona compared to sites more distant from the foreskin. There was, however, weak evidence that circumcision was associated with changes in HPV incidence and clearance and no evidence of a favorable effect on genital warts. Larke $\mathrm{N}$ et al. concluded that male circumcision reduces HPV prevalence.

\section{Conclusions and recommendations for future research}

In this review, we have discussed the strong interrelationship between two sexually transmitted viruses: HIV and HPV. HPV infection is more common and more likely to persist in HIV-positive versus HIV-negative women. The burden of disease associated with infection with HPV, particularly high-risk types, is considerable and there is a strong association between HIV infection and anogenital cancers and their precursors. HPV is believed to be more dangerous among HIV-positive individuals due to the impact of HIV on cell-mediated immunity, a critical component required for clearance of HPV infection. Linkage studies with HIV/AIDS and cancer registries have shown a 2 - to 22 -fold increase in invasive cancer in HIV-positive women compared to the general female population, depending upon screening and competing mortality. HIV-positive women with cervical cancer are more likely to have multiple HPV infections, but HPV16 and/or 18 prevalence in cervical cancer was similar in HIV-positive and -negative women, suggesting that the current HPV vaccines may prevent a similar proportion of cervical cancers regardless of HIV status.

It is not clear whether HPV infection increases the risk of HIV acquisition although data are accruing that the inflammatory response evoked by HPV may solicit cells that are vulnerable to HIV infection. This is an important area for future research, as it would make the prevention of HPV infection even more urgent.

Vertical transmission of HPV and HIV from mother to child is well documented, and perinatally infected children are more likely to be HPV-infected. The impact of current HPV vaccines in HIVinfected children is unknown, but one study has shown nearly $100 \%$ seroconversion after vaccination of children with the quadrivalent vaccine, although antibody titers were lower than for HIV-negative children. The efficacy of HPV vaccination in HIV-positive children requires further research.

The incidence of anal cancer appears to be rising, particularly in HIV-infected individuals and especially in HIV-positive MSM. Anal cancer has a well known precursor stage that can be detected in a variety of ways, including anal cytology and high-resolution anoscopy. It is unknown at this point whether screening for and treating anal precursors will reduce the incidence of anal cancer and no randomized trials have been performed. This is another important area for research.

Options for the prevention of HPV-associated cancers include HPV vaccination (yet to be shown to be efficacious in HIV-infected individuals) and male circumcision, among other interventions related to sexual health and behaviors, lifestyle habits (smoking) and others still to be identified.

\section{Acknowledgements}

The work was partially supported by Bill and Melinda Gates Foundation, USA (35537), public grants from the European Commission (7th Framework Programme grants HEALTH-F3-2010242061, PREHDICT), from the Instituto de Salud Carlos III (Spanish Government) (grants FIS PI10/02995, RCESP C03/09, RTICESP C03/10, RTIC RD06/0020/0095 and CIBERESP), from the Agència de Gestió d'Ajuts Universitaris i de Recerca - Generalitat de Catalunya
(Catalonian Government) (grants AGAUR 2005SGR00695 and AGAUR 2009SGR126), who had no role in data collection, analysis or interpretation of results.

\section{Disclosed potential conflicts of interest}

LD: Has received honoraria from GlaxoSmithKline and Merck and Co. for appearing on various speaker fora and sponsorship for research studies.

SF and IH: Have no potential conflicts of interest to declare.

SdS: Institutional support: HPV vaccine trials and epidemiological studies sponsored by GlaxoSmithKline, Merck and Co., and Sanofi Pasteur MSD. Screening and HPV testing trials partially supported by Qiagen. Personal support: Travel grants to conferences/symposia/meetings are occasionally granted by either GlaxoSmithKline, Sanofi Pasteur MSD or Qiagen.

ABM: Merck and Co., and GlaxoSmithKline.

JP: Merck and Co., and Pharmajet.

\section{References}

[1] [1993] revised classification system for HIV infection and expanded surveillance case definition for AIDS among adolescents and adults MMWR Recommit Rep 1992; 41:1-19.

[2] De Vuyst H, Lillo F, Broutet N, Smith JS. HIV, human papillomavirus, and cervical neoplasia and cancer in the era of highly active antiretroviral therapy. Eur J Cancer Prev 2008 b; 17:545-54.

[3] Harris TG, Burk RB, Palefsky JM, Massed LS, Bang JY, Anastos K, et al. Incidence of cervical squamous intraepithelial lesions associated with HIV serostatus, CD4 cell counts, and human papillomavirus test results. JAMA 2005;293: 1471-6.

[4] Singh D, Anastos K, Hoover D, Burk R, Shi Q, Ngendahayo L, et al. Human papillomavirus infection and cervical cytology in HIV-infected and HIV-uninfected Rwandan women. J Infect Dis 2009;199(12):1851-61.

[5] Denny L, Boa R, Williamson AL, Allan B, Hardie D, Ress S, et al. Human papillomavirus infection and cervical disease in human immunodeficiency virus-1 infected women. Obstet Gynecol 2008;111(6):1380-7.

[6] Clifford GM, Goncalves MA, Franceschi S, HPV, HIV study group. Human papillomavirus types among women infected with HIV: a meta-analyisis. AIDS 2006;20(18):2337-44.

[7] Veldhuizen NJ, Braunstein SL, Vyankandondera J, Ingabire C, Ntirushwa J, Kestelyn E. The epidemiology of human papillomavirus infection in HIV-positive and HIV-negative high-risk women in Kigali, Rwanda. BMC Infect Dis 2011;11:333.

[8] Palefsky J. Human papillomavirus-related disease in people with HIV. Curr Opin HIV AIDS 2009;4(1):52-6.

[9] Walboomers JM, Jacobs MV, Manos MM, Bosch FX, Kummer JA, Shah KV, et al. Human papillomavirus is a necessary cause of invasive cervical cancer worldwide. J Pathol 1999;189(1):12-9.

[10] Parkin DM, Louie KS, Clifford G. Burden and trends of type-specific human papillomavirus infections and related diseases in the Asia Pacific region. Vaccine 2008;26(Suppl 12):M1-16.

[11] Chaturvedi AK, Madeleine MM, Biggar RJ, Engels EA., Risk of human papillomavirus-associated cancers among persons with AIDS. 2009;101;16: $1120-30$

[12] Silverberg MJ, Chao C, Leyden WA, Xu L, Horberg MA, Klein D. HIV infection, immunodeficiency, viral replication and the risk of cancer. Cancer Epidemiol Biomarkers Prev 2011;20(12):2551-9.

[13] Minkoff H, Zhong Y, Burk RD, Palefsky JM, Xue X, Heather Watts D, et al. Influence of adherent and effective antiretroviral therapy use on human papillomavirus infection and squamous intraepithelial lesions in human immunodeficiency virus-positive women. JID 2010;201:681-90.

[14] Li N, Franceschi S, Howell-Jones R, Snijders PJ, Clifford GM. Human papillomavirus type distribution in 30,848 invasive cervical cancers worldwide: Variation by geographical region, histological type and year of publication. Int J Cancer 2011;128:927-35.

[15] De Vuyst H, Gichangi PB, Estambale B, Njuguna E, Franceschi S, Temmerman M. Human papillomavirus types in women with invasive cervical carcinoma by HIV status in Kenya. Int J Cancer 2008;122:244-6.

[16] Odida M, Sandin S, Mirembe F, Kleter B, Quint W, Weiderpass E. HPV types, HIV and invasive cervical carcinoma risk in Kampala, Uganda: a case-control study. Infect Agent Cancer 2011;6:8.

[17] De Vuyst H, Ndirangu G, Moodley M, Tenet V, Estambale B, Meijer CJLM, et al. Prevalence of human papillomavirus in women with invasive cervical carcinoma by HIV status in Kenya and South Africa. Int J Cancer 2011 Sep 29, http://dx.doi.org/10.1002/ijc.26470.

[18] Naucler P, da Costa FM, Da Costa JL, Ljungberg O, Bugalho A, Dilner J. Human papillomavirus type-specific risk of cervical cancer in a population with high human immunodeficiency virus prevalences: case - control study. J Gen Virol 2011;92:2784-91. 
[19] Sahasrabuddhe VV, Mwanahamuntu MH, Vermund SH, Huh WK, Lyon MD, Stringer JS, et al. Prevalence and distribution of HPV genotypes among HIVinfected women in Zambia. Br J Cancer 2007;96:1480-3.

[20] de Sanjose S, Quint WG, Alemany L, Geraets DT, Klaustermeier JE, Lloveras $B$, et al. Human papillomavirus genotype attribution in invasive cervical cancer: a retrospective cross-sectional worldwide study. Lancet Oncol 2010;11:1048-56.

[21] Chaturvedi AK, Madeleine MM, Biggar RJ, Engels EA. Risk of human papillomavirus-associated cancers among persons with AIDS. J Natl Cancer Inst 2009;101:1120-30.

[22] Lacey CJ. Therapy for genital human papillomavirus-related disease. J Clin Virol 2005;32(Suppl 1):S82-90.

[23] Chin-Hong PV, Husnik M, Cranston RD, Colfax G, Buchbinder S, Da Costa M, et al. Anal human papillomavirus infection is associated with HIV acquisition in men who have sex with men. AIDS 2009;23(9):1135-42.

[24] Smith JS, Moses S, Hudgens M, Parker CB, Agot K, Maclean I, et al. Increased risk of HIV acquisition among Kenyan men with human papillomavirus infection. J Infect Dis 2010;201(11):1677-85.

[25] Smith-McCune KK, Shiboski S, Chirenje MZ, Magure T, Tuveson J, Ma Y, et al. Type-specific cervico-vaginal human papillomavirus infection increases risk of HIV acquisition independent of other sexually transmitted infections. PLoS One 2010;5(4).

[26] Brogly SB, Watts DH, Ylitalo N, Franco EL, Seage 3rd GR, Oleske J, et al. Reproductive health of adolescent girls perinatally infected with HIV. Am J Public Health 2007;97:1047-52.

[27] Nachman S, Chernoff M, Gona P, Van Dyke RB, Dankner WM, Seage 3rd $\mathrm{GR}$, et al. Incidence of non infectious conditions in perinatally HIV infected children and adolescents in the HAART Era. Archiv Pediatrc Adolesc Med 2009;163(2):164-71.

[28] Magalhaes MG, Bueno DF, Serra E, Goncalves R. Oral manifestations of HIV positive children. Clin Pediatr Dent 2001;25:103-6.

[29] Pinheiro RS, de Franca TR, Rocha B, Ferreira DC, Ribeiro CM, Cavalcanti SM, et al. HPV co-infection in the oral cavity of HIV-infected children. J Clin Path 2011;64(12):1083-7

[30] Levin M, Moscicki A, Song L, Fenton T, Meyer 3rd WA, Read JS, et al. Safety and immunogenicity of a quadrivalent human papillomavirus (Types $6,11,16$, and 18) vaccine in HIV-infected children 7 to 12 years old. J Acquir Immun Defic Syndr 2010;55(2):197-204.

[31] De Vuyst $H$, Clifford GM, Nascimento MC Madeleine MM, Franceschi S. Prevalence and type distribution of human papillomavirus in carcinoma and intraepithelial neoplasia of the vulva, vagina and anus: a meta-analysis. Int J Cancer 2009;124(7):1626-36.

[32] Hoots BE, Palefsky JM, Pimenta JM, Smith JS. Human papillomavirus type distribution in anal cancer and anal intraepithelial lesions. Int J Cancer 2009; 124(10):2375-83.
[33] Watson AJ, Smith BB, Whitehead MR, Sykes PH, Frizelle FA. Malignant progression of anal intra-epithelial neoplasia. ANZ J Surg 2006;76(8):715-7.

[34] Johnson LG, Madeleine MM, Newcomer LM, Schwartz SM, Daling JR. Anal cancer incidence and survival: the surveillance, epidemiology, and end results experience, 1973-2000. Cancer 2004;101(2): 281-8.

[35] Palefsky JM, Holly EA, Efirdc JT, Da Costa M, Jay N, Berry JM, et al. Anal intraepithelial neoplasia in the highly active antiretroviral therapy era among HIV-positive men who have sex with men. AIDS 2005;19(13): 1407-14.

[36] Frisch M, Biggar RJ, Goedert JJ. Human papillomavirus-associated cancers in patients with human immunodeficiency virus infection and acquired immunodeficiency syndrome. J Natl Cancer Inst 2000;92(18):1500-10.

37] Shiels MS, Pfeiffer RM, Gail MH, Hall HI, Li J, Chaturvedi AK, et al. Cancer burden in the HIV-infected population in the United States. J Natl Cancer Inst 2011;103(9):753-62.

[38] Berry JM, Palefsky JM, Jay N, Cheng SC, Darragh TM, Chin-Hong PV. Performance characteristics of anal cytology and human papillomavirus testing in patients with high-resolution anoscopy-guided biopsy of high-grade anal intraepithelial neoplasia. Dis Colon Rectum 2009;52(2): 239-47.

[39] Darragh TM, Winkler B. Anal cancer and cervical cancer screening: Key differences. Cancer Cytopathol 2011;119(1):5-19.

[40] Goldie SJ, Kuntz KM, Weinstein MC, Freedberg KA, Welton ML, Palefsky JM. The clinical effectiveness and cost-effectiveness of screening for anal squamous intraepithelial lesions in homosexual and bisexual HIV-positive men. JAMA 1999;281(19):1822-9.

[41] Denny L, Hendricks B, Gordon C, Thomas F, Hezareh M, Dobbelaere K, et al Safety and immunogenicity of the HPV -16/18 ASO4- adjuvanted vaccine in HIV positive women in South Africa. Abstract no.599. In: AORTIC $7^{\text {th }}$ Internationa Conference. 2011.

[42] Siegfried N, Muller M, Deeks JJ, Volmink J. Male Circumcision for prevention of heterosexual acquisition of HIV in men. Cochrane Database Syst Rev 2009;(2) CD003362.

[43] Tobian AA, Serwadda D, Quinn TC, Kigozi G, Gravitt PE, Laeyendecker O, et al. Male circumcision for the prevention of HSV-2 and HPV infection and syphilis. N Engl J Med 2009;360:1298-309.

[44] Sobngwi-Tambekou J, Taljaard D, Nieuwoudt M, Lissouba P, Puren A, Auvert B. Male circumcision and Neisseria gonorrheae, Chlamydia trachomatis and Trichomonas vaginalis: observations after a randomised controlled trial for HPV prevention. Sex Trans Infect 2009;85:116-20.

45] Larke N, Thomas SL, dos Santos SI, Weiss HA. Male circumcision and human papillomavirus infection in men: A systematic review and meta-analysis. J Infect Dis 2011;204:1375-90. 